\title{
Prehistoric Times of Pondicherry
}

\author{
Ravitchandirane Perumal* \\ History Department, Tagore Arts College, Government of Pondicherry, \\ Pondicherry, India; perravi0805@gmail.com
}

\begin{abstract}
The origin of Pondicherry is buried in legends. M. G. Jouveau Dubreuil, the French mathematician, believed that the town was once called as Vedapuri and was a seat of Vedic culture and the abode of Sage Agastya. The Ashram of Agastya was on the very spot where the main building of Sri Aurobindo Ashram stands today. However, this legend is believed even today by some scholars who make it as true history through some of their publications and one among them is the Gazetteer of Pondicherry.

Based on the Mediterranean materials found at Arikamedu, Wheeler undoubtedly believed that Pondicherry was an ancient sea-port. This has been often compared to the 'Poduke Emporium' of classical writers. However, since Casals, J.M and G hitherto believed that the early settlement of Pondicherry as late-chalcolithic and that it has moved towards the end of the second century BC or contemporaries of Iron Age settlement of Arikamedu. Recently Sundara has compared the stone axes, certain forms and decorative motifs on grey ware, which were found on the surface and in the excavations of Arikamedu, with Neolithic times. The previous studies on early history of Pondicherry, focusing on the external trade of Pondicherry, contributed greatly to the emergence of an international port-town in the early Christian era, which had many production centers of beads and textiles.

No specific study on prehistoric times of Pondicherry, though it was a prominent commercial production center and an international seaport during early Christian era, has been made until now. The present work, therefore, is an attempt to explore the early human activity and habitation, which led to the urbanization of Pondicherry.
\end{abstract}

Keywords: Acheulian, Holocene, Laterite, Megalithic, Mesolithic, MicrolithicNeo-chalcolithic, Neolithic, Paleolithic, Pleistocene, Proto-historic Age, Quartzite

\section{Introduction}

Neglecting prehistory is highly reflected in Pondicherry. No prehistoric study is so far carried out in this region even though the region has many geological formations and fossils with in its small area. 'The Early History of Pondicherry' began with Sangam literature in relation with the Arikamedu excavation report of Wheeler.

Many living organisms in the prehistoric times of Pondicherry are traced. However, the evidence of the presence of human beings during this age in this region is none. Recently excavation was carried out at Attirampakkam, which was characterized as a type-site of Acheulian hand axe-based Madras Industries, is situated in the Kortallayar river basin, Tamilnadu [1]. These discoveries within the broader regional setting would be able to contribute towards the study of early hominid behaviour during the Middle and Late Pleistocene in South India.

To understand the prehistoric age of Pondicherry and to trace out the early presence of human in this area, the history tends with Archaeology, Geology, Paleontology, Paleo-botany, Biological Anthropology and Archaeological Chemistry.

\section{Prehistoric Climate in Pondicherry}

The pattern of wet and dry periods (Pluvial and interPluvial) for a considerable part of south India was suggested by Burkitt [2] and later confirmed by Zeuner [3]. It was noticed that the climatic changes that took place in

${ }^{*}$ Author for correspondence 
South India were, to a large extent, linked up with the origin of laterite, the peculiar sub aerial alteration product and a widely occurring geological formation.

The formation of laterite [4], a decayed clayey mass, consisting largely of hydrated silicate of alumina and iron, can only take place where there is a considerable rainfall. In fact, Laterite forms only in tropical areas, and that too in the areas of very heavy rainfall. It would appear that waterlogging of the soil is an important condition for its formation. It is likely that there might have been an alternation of distinct wet and dry seasons in South India. The presence of extensive deposits of laterite may indicate that the pluvial or wet period might have been very protracted.

\section{Prehistoric Human Remains}

The presence of prehistoric man in Pondicherry maybe traced with the raw materials and the geological location. The Kaluvali Lake almost blocked the movement of prehistoric man to this land. The Kaluvali Lake was formed after fluctuations of the sea as in the Red hills of Pulicat Lake near Chennai.

The study was done on the new discoveries and also by using earlier findings so as to see the complete picture of the cultural development. There are evidences from Lower Paleolithic to Megalithic with continuation into early historical sites in the valley along the banks of the river Gingee and from lateritic high ground. The study tried to find the prehistoric sites in primary and stratified contexts, which enable to understand at least the traces of prehistoric presence of human being. It was a micro-regional study where more emphasis was given on the Prehistoric culture besides dealing with the outlines of the Neolithic and Megalithic cultures.

\section{Paleolithic Evidence from Pondicherry}

The distribution of Paleolithic sites was done in relation to their topographical settings against the background of their ecology, raw materials, water source and quaternary deposits, and established the man - land relationship within the chronological frame work. The quaternary deposits were found in the form of High Level Gravels and Older Alluvium, somehow or other which are related to the sites that help to draw the climatic conditions, and that at least there were two cycles of wet and dry climatic phases during Stone Age times.

There is no chance of having taken ethnographic analogy from the local tribe for the Prehistoric age. If so, it might have given insights as regards the seasonal migrations, types of temporary dwellings, their hunting practices and food economy. However, such types of temporary dwellings could not be traced in Pondicherry region.

Only one hand axe from Usudu [5], now in Pondicherry museum, is an undisputable evidence for the prehistory (Figure 1). However, there is no record on the precise location of the site, or from where the artefact was collected is not known, except that it was from the Pondicherry area.

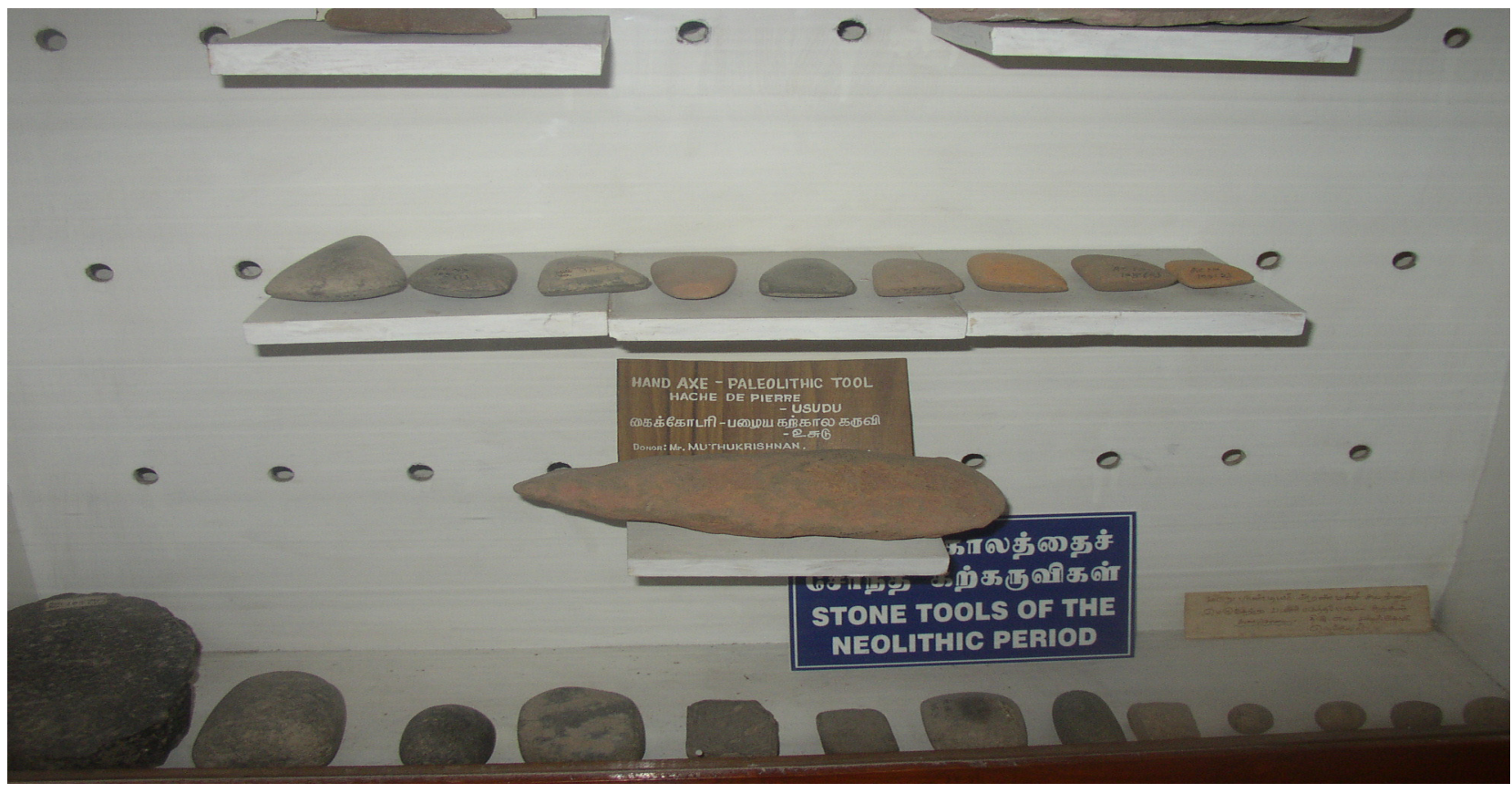

Figure 1. Hand axe said to be found near Usudu Lake, Pondicherry Museum. 
The pebbles from the Thiruvakkarai and Auroville region indicate the possibilities of Paleolithic but so far none of the samples has been recorded. The hand axe from Usudu lake area is not that much sufficient to study the Paleolithic age of Pondicherry region.

\section{Pre-historic Tools from the Early Study}

In the early 20th century, the French scholars, after the Arikamedu excavations, focused on the Iron Age burials which led them to discover some of the Neolithic type tools. The establishment of the Museum in Pondicherry made possible to collect some of the stone tools for display.

Lake Usudu is located about 20 kilometers west of Pondicherry and part of the lake is now in the neighbouring state, Tamilnadu. The Red soil mound sloping against the lake at the east, west and north part of the lake are under cultivation. The lake is fed with canyons from the eastern slopes. A hand axe is found from this lake side. At present, the only one hand axe which is displayed in Pondicherry Museum seems to be the single virtual source to speak about the Early Paleolithic in Pondicherry. However, there is no record on when and who discovered it.

\section{Prehistoric Traces from the Recent Study}

The exploration conducted on the red soil formation formed at the north and north east of Pondicherry helps to find out the presence of the prehistoric traces. The red hill range which spreads from the east to the west of 40 kilometers with a break in the region of Kadaperi and Ottai yields clay, the raw material for stone tool industries of the prehistoric age. The study identified pebble deposits at the west end of the Red soil over Thiruvakkarai and at the east end of Auroville.

\subsection{Thiruvakkarai and Auroville}

The Thiruvakkarai village is located at the western boundary of Pondicherry and is located in Vilupuram district of Tamilnadu. Auroville, an international city is located at $10 \mathrm{~km}$ north of Pondicherry. Both are located on an elevated red soil mounds. At Thiruvakkarai, a large number of rounded pebbles and cobbles spread all over the slopes of the canyons.

For the past 25 years, none of the tools has been so far reported from this region. However, at Auroville, only one flake of quartzite pebble possibly belonging to late Paleolithic is found from the Iron Age burial excavations. Recently the Department of History, Pondicherry University carried out an excavation in the campus under the direction of Dr. Rajanedran from Kerala, and found the flakes of quartzite pebbles and angular fragments of sandstone and quartzite core. However, the excavated quartzite pebbles are not published or even displayed.

\section{Traces of Mesolithic}

A Mesolithic horizon comparable to that of the Teri (red soil) sites of the Coromandal coast - dating from ca. 40,000 $\mathrm{BP}[6]$, and perhaps as early as the beginning of Holocene ca. 9,000 BP may have existed in the Pondicherry region as well. The Teris are consolidated dunes which presumably camped among them [7]. The Industry consists of "microlithic" flake tools made predominantly from quartz and chert.

The quartz is found in large in the high ground of the western part of Pondicherry, and the red soil stretches from Thiruvakkarai and Kalapet-Auroville region. The study found that some of the flakes of quartz pebble resembling the upper Paleolithic tools are occasionally seen in Pondicherry University campus of Kalapet and in the region of Auroville.

Preliminary surveys carried out in the surroundings of Pondicherry, in the Teri deposit Red uplands, have tried to find the presence of Mesolithic, early Holocene, stations on the top of the sand dunes bordering the lakes that characterize the region. The first survey for the Mesolithic site in the area was made in March 1995, when a very less lithic assemblage, including upper Paleolithic flakes, were collected from the surface of a fixed dune in Auroville.

M. Soundararajan has stated that perhaps this region [8] is from the lateritic highground formed in the west of Pondicherry. However, he has mentioned that the tools of chert, chalcedony, crystal, agate and japer have not been seen in this region.

A small collection of stone artefacts made by Bonnois, now in the Musée de l'Homme in Paris was published by Zuener [9]. The precise location of the site, from where the tools were collected, is not recorded. However, there is a note that they are from Pondicherry. The flaked tools are all of chert and other kinds of silica, and the whole assemblage is typical of south Indian Neolithic [9]. The tools are stained reddish brown like those from the Teri sites, but whether this was due to hydrated ferric oxide, or other factors, is not certain.

\section{Neolithic in Pondicherry}

There is no trace of Neolithic industries in Pondicherry region. The Neolithic type polished axes are found both in the excavations and surfaces of the protohistoric age sites in Pondicherry. The polished stone axes, however, are 


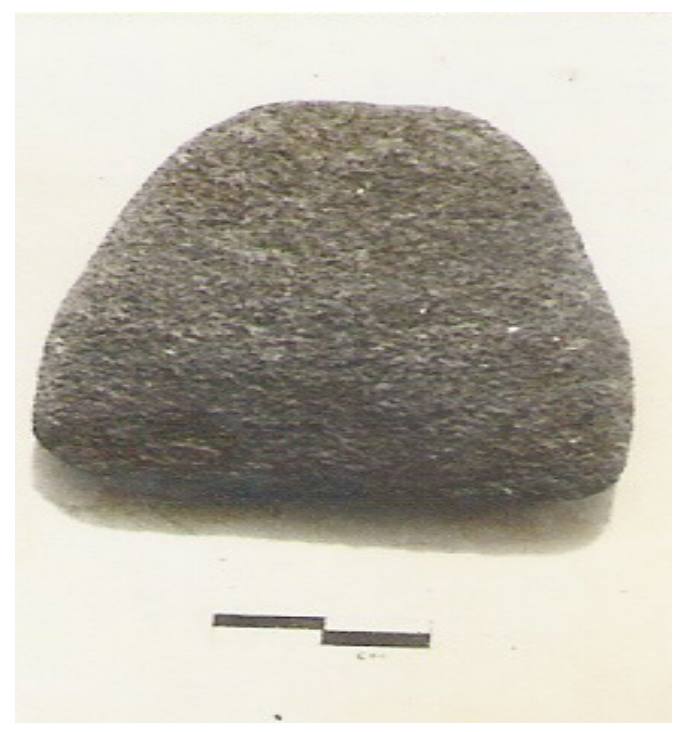

Figure 2. a. Neolithic type tool, Auroville.

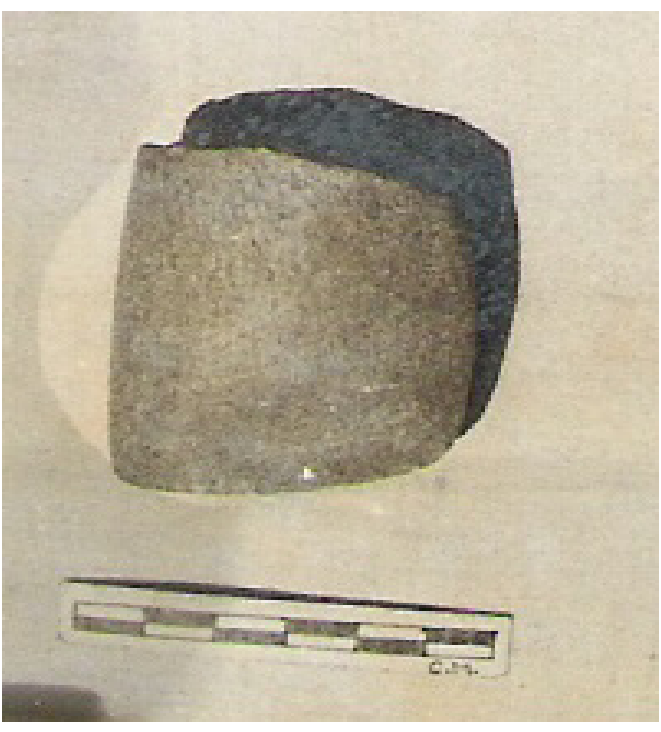

b. Neolithic type tool, Sorapattu. important tools and should be pursued further. The Neolithic type polished stone axes are found in the sites like Gorimedu, Mangalam, Arikamedu, Sorapattu (Figure 2b), Auroville (Figure 2a) and Perimbe [10].

\subsection{Gorimedu}

Archaeological materials are collected on the surface at Gorimedu and its immediate vicinity sites such as Mattukaranchavadi and Morattandi which are now located $3 \mathrm{~km}$ north of Pondicherry on the Tindivanam-Pondicherry national highway. Geographically speaking these sites are located on the Coudalore formation and thirty meters above the sea level. Most of the lands are of red clay and pebble-and-gravel mixture. Here, the cultivation is mostly dry, like peanuts during rainy seasons.

CasalandCasalreportenablesthis areaasneo-chalcolithic after some collections by F. Faucheux. In 1950, father Faucheux collected some potsherds and other artefacts on the surface of Gorimedu and brought to Casals for identification. Casals basically identified that some of his collection were of neo-chalcolithic age after some Neolithic type tools he found in the Iron age burials in Pondicherry. In the report, Casals noted that Faucheux's collection of pottery, a stone object and a bronze bracelet were studied and published in 1956 [11]. Faucheux stored his collections in Petit Séminaire School in Pondicherry. Unfortunately, now these collections are not found in the school.

Casals identified that the Faucheux's collection of perforated black lid [12] is commonly noticed in the modern pottery, which is generally of handmade and is black or red in color. Casals described this as a black surfaced handmade lid. Even in the modern days this type of lid is used to filter the cooked rice. In addition, the illustrated materials have been found on the surface and not from the excavation which is very hard to date without any comparative sample.

A bronze bracelet with trumpet ends from Faucheux's collection, illustrated by Casals [13] does not fit into the known peninsular Neolithic assemblage [14]. Hence, the Casals' report is not sufficient to conclude that Gorimedu is a Neolithic assemble site. At present, the study found no such evidence on the surface of Gorimedu and its vicinity. However, close to Gorimedu, the study found some protohistoric artefacts on the surface and a terracotta ring well.

\subsection{Mangalam}

Mangalam is located near Villionur in Pondicherry. A road, on the south-west bank from the south-west end of a bridge over the river Gingee leads towards the Mangalam village from Villionur. A stone tool was identified as from the collections of father Faucheux. However, it was published with a little illustration but without any description by Casals as neo-chalcolithic.

The urns that have been found in Mangalam raise many questions regarding the date and culture. However, in 1983, an excavation was carried out by Archaeological Survey of India at Mangalam but it is not proposed as a reliable solution regarding the above problem. Obviously, there are two Mangalams apart from this village Mangalam. They are Mel-Satha Mangalam and Kil-Satha Mangalam. A road, on the south-west bank from the south-west end of a bridge across the river Gingee leads to the village Mangalam. Mangalam was identified as a neo-chalcolithic urn burial site by Casals in 1950. However, the materials illustrated by Casals are very least to draw this conclusion. 


\section{Chronology of Neolithic Tools from Pondicherry}

Neolithic-chalcolithic type polished stone axes were found among the artefacts associated with some cemetery sites in Pondicherry region. However, there is, as yet, no conclusive evidence for the existence of a Neolithic or Chalcolithic settlement, although such settlement sites were excavated in other parts of the peninsula. In Pondicherry, there are several large cemeteries such as Gorimedu, Mangalam, Perimbe, Muthrapaleaon and Suttukeni (Figure 3) described by Laffitte [15] and Casals [16]. These cemeteries, generally speaking, represent two basic types of graves; Urn burials with or without surviving stone circles; and cist burials occasionally, as at Suttukeni, containing sarcophagi within a cist. Except a grave at Perimbe, where a complete burial was found within a terracotta sarcophagus, the other burials were fractional. Although many of the burials were akin to the Iron Age (so called megalithic) complex of South India, in some cases the assemblages associated with them include Chalcolithic type of artefacts.

At Perimbe cemetery, polished stone axes were found along with the Iron Age (megalithic burial) black-and-red ware and iron objects. Casal and Casal assign this cemetery to an intermediate phase between the Chalcolithic ones at Gorimedu and Mangalam on one hand, and the Iron Age ones at Muthrapaleaon and Suttukeni on the other [17].

Casal and Casal have proposed a chronological sequence for the cemetery sites based upon the artefacts associated with them [17]. They consider the Chalcolithic period dating from pre-second century BC. The burials at these two sites are without "Megalithic" black-and-red ware and iron objects - both considered to be characteristic of the Iron Age graves, as funerary deposits. Furthermore, they consider the pottery recovered from these graves have greater affinity to wares of the Chalcolithic (stone-axe period at Brahmagri) [18] than to the nearby Iron Age cemetery at Muthrapaleaon. In addition, numerous stone axes were said to be found on the surface of these two cemeteries.

The combination of all these factors cannot be ignored; and is suggestive of, if not earlier chronologically, at least, a culturally distinct burial group when compared to other cemetery sites in the area, and the South Indian Iron Age complex in general. Megalithic sites of pre or non-iron association are known in Western Deccan [19], but the two complexes cannot be correlated at present.

Allchin and Allchin also have considered Gorimedu and Mangalam as cemeteries of the late Chalcolithic period. However, the Iron Age complex of South India is so varied and difficult to date on the basis of artefact association alone that the chronology suggested by Casals should only be considered as tentative, to be tested in this study. As L. Leshnik points out, some artefacts such as the bronze bracelet with trumpet ends from Gorimedu have parallels in the Iron Age groves. The clay hooks attached to the inside of the large jars at Perimbe, and the sarcophagus at Suttukeni provide links between the two cemeteries of Pondicherry group on the one hand as well as with the Iron Age cemetery at Pomparippu in Sri Lanka on the other [20].

The question of polished stone axes is an important one and should be pursued further. Their presence at Gorimedu, Mangalam and Perimbe could be construed as a result of trade exchange in horizontally coexisting but technologically different cultures, as was and still is, quite common in the Indian subcontinent - instead of representing an earlier Chalcolithic archaeology horizon. Some of the stone axes, now in Pondicherry Museum, are now stained reddish brown, like the stone tools from the Bonnois collection

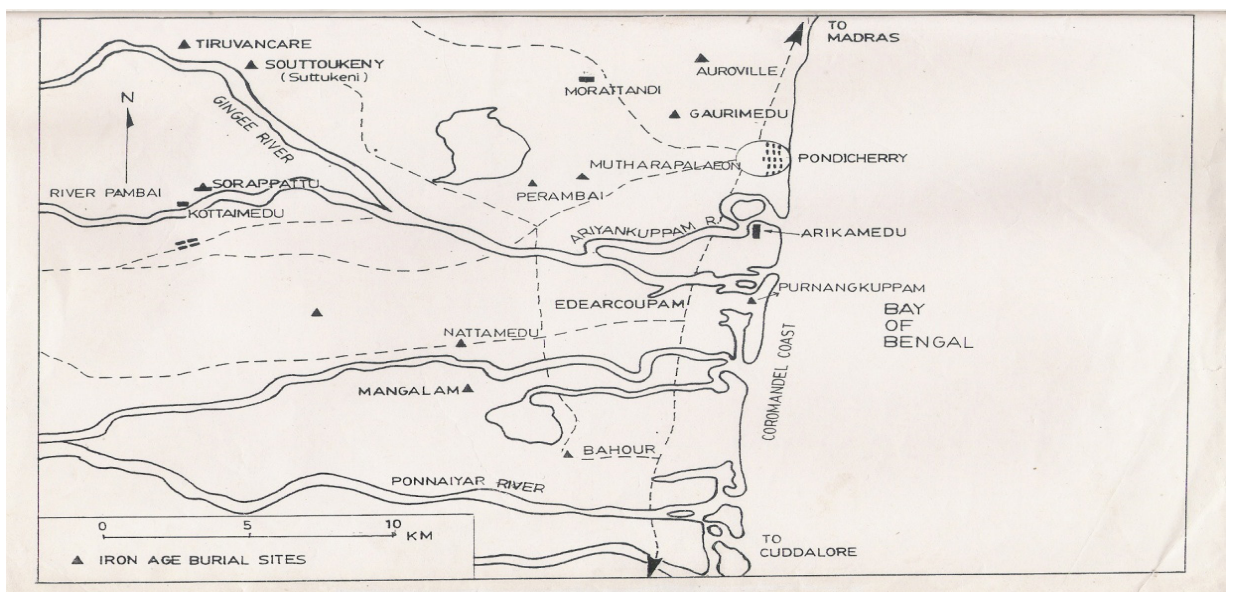

Figure 3. Map of iron age sites in Pondicherry area (after Casals). 
mentioned earlier, the significance of which remains to be determined.

Furthermore, Neolithic type stone tools were said to be found at Mel Satha-Mangalam, a site not too far from Mangalam, where trial excavations were conducted by the Archaeological Survey of India in February 1983. If so, it would seem that there was an actual settlement of the Chalcolithic period in the region, which could provide a context for the cemetery sites as well. Unfortunately the Mel Satha-Mangalam material has not yet been published. The question should be pursued further when the Mel Satha-Mangalam materials are published.

Casal and Casal date the Suttukeni-Muthrapaleaon group to the second-first century BC., time period, which falls within the range of dates from Iron Age complex in eastern Tamil Nadu. In this case, these cemetery groups must have been contemporary with the early phases of the settlement at Arikamedu, which was a port city in early Christian era. It is likely that there was some interaction between Suttukeni-Thiruvakkarai and Arikamedu. Not only are the two sites located along the same river system, but the artefact assemblage from the cist burial at Suttukeni also seem to imply some foreign influence, and Arikamedu is a trading centre from the second century BC., onwards. This factor, however, is noted in the emergence of city in Pondicherry.

Recently a fragment of a stone axe, presently in Pondicherry Museum, was picked up in the dry bed of the Pambai Vayakkal at Sorapattu along with the Iron Age pottery in the adjacent fields [21]. One highly damaged Neolithic type tool, now in Auroville Museum was recovered from Kuilapalayam, a kilometer south east of Iron Age burials of Auroville. Almost all recovered Neolithic type tools were from the Iron Age burials which show that the Neolithic type tools were in usage even during the proto-historic age of Pondicherry.

\section{Neolithic Type Tools in Proto-historic Age}

The evidence of a polished stone axe found in Wheeler's pre-structural phase in the southern sector of Arikamedu and certain forms and decorative motifs on grey ware in the northern sector of Arikamedu have made A. Sundara to conclude that there was a Neolithic habitation located in the low-lying area of the northern sector of Arikamedu. Sundara has suggested that there was a Neolithic habitation located in the northern sector and beside a sandy hillock in the southern sector [22]. He states, "It was in this small Neolithic habitation site almost practically deserted that people of the early historical period with the imported pottery settled" [24]. His conclusion is based upon two factors: first, the stone hand-axe found in Wheeler's pre-structural phase in the Southern sector [23], and second, certain pottery forms and decorative motifs on gray ware in Northern sector.

It is true that at Arikamedu, from the surface and occasionally in the trenches as well, Neolithic type stone-axes were found with pointed butts, such as the example cited above. Two fragments of stone axes were found by Begley on the surface in the northern sector and one fragment in excavation [24]. The fragments from her investigation are not from the primary deposits, but they are from Wheeler's pre-structural phase in the southern sector which would appear to be equated with Casals' megalithic period.

Since there is, as yet, no other evidence for a pre-iron age settlement at Arikamedu, the stone axes are not likely to represent a Neolithic archaeological horizon; they suggest either reuse or survival of an earlier form of tool in Iron Age and early historical cultures in the area. Stone hand axes were recovered from other sites in the vicinity of Arikamedu, such as Mangalam, Perimbe and Gorimedu, Sorapattu and Auroville. Neolithic type stone axes might have been used by the first settlers at Arikamedu as well, but not of Pre-iron Age times.

\section{Perceptions of Neolithic Ceramic in Pondicherry Region}

At Arikamedu, A. Sundara has cited the pottery and equated it to the stone axe culture of Brahmagri, but it should be remembered that some of the Neolithic/Chalcolithic forms survived in the so called megalithic cultures of South India includes Arikamedu also. The incised decoration mentioned by Sundara occurs at Muthrapaleaon also. There are other parallels as well between the pottery at Arikamedu and in the vicinity of the late Iron Age burial sites. In short, there is a carryover of several forms of the earlier cultures into the trade period of Arikamedu, but no evidence of a Neolithic cultural or chronological horizon is found in the archaeological records. Sundara has not taken into account of Casals' work at Arikamedu or at the burial sites in the Pondicherry region.

\section{Conclusion}

All the above collected materials and analyses prove that there is no settlement or habitation of pre-historic age in 
Pondicherry. A few upper Paleolithic flakes from Auroville and in Pondicherry University Campus found recently are not much sufficient sources to conclude traces of habitation during late Paleolithic or Mesolithic. However, it might have been a seasonal habitation or some time those materials might have been used by the Proto-historic Iron Age settlers habitated in various places of Pondicherry with different economic backgrounds. The Neolithic tools from the various Iron Age burials and habitations also illustrate that the Iron Age folk possibly used these Neolithic type polished stone tools.

\section{References}

1. Pappu S., "Excavations at the Palaeolithic Site of Attirampakkam, South India”, Antiquity, vol. 77(297), Sep. 2003.

2. Cannuade L. A., and Burkitt M. C., "Fresh light on the stone Age of South East India”, Antiquity, vol. IV, p. 328-330, 1930.

3. Zeuner F. E., Stone Age and Pleistocene Chronology in Gujarat, p. 42, 1942.

4. Wadia D. N., Geology of India, p. 376-380, 1919.

5. Rajaram K., "Puduvai Karkala Konduppedippu”, Varalattruchsuvaduka, vol. I., p. 93, 1982.

6. Zeuner F. E., and Allchin B., "The Microlithic sites of Tinnevelly District, Madras state”, Ancient India, vol. 12, p. 4-20, 1956.

7. Allchin B., and Allchin F. R., The Rise of Civilization in India and Pakistan. Cambridge, p. 87, 1982.

8. Soundararajan M., "Prehistoric, protohistoric and archaeological periods", Gazetteer of India, Union Territory of Pondicherry, vol. I, p. 129, 1980.

9. Zeuner F. E., and Allchin B., op. cit., p. 4-20, 1956.

10. Ravitchandirane P., The Iron Age culture, Pondicherry, 1994, unpublished report submitted to PLIC. See also
Casal J. M., and Casal G., Site Urbain et Sites Funéraires des Environs de Pondichéry Paris. 1956: p. 119-129, Wheeler, R.E.M., Ghosh A., and Deva K., "Arikamedu: an Indo Roman Trading Station on the East Coast of India", Ancient India, vol. 2, p. 17-125, 1946. Soundrarajan.M., op. cit., p. $129,1980$.

11. Casal J. M., and Casal G., op. cit., 1956.

12. Casal J. M., and Casal G., op. cit., Fig. 38, 1956. Fig. 38 type 309.

13. Casal J. M., and Casal G., op. cit.

14. Leshnik L. S., South Indian Megalithic Burials, The Pandukal Comple. Wiesbaden, 1974.

15. Laffitte N., Rapport d'ensembles sur les fouilles exécutées dans le sud de l'Inde. Paris, 1932.

16. Casal J. M., and Casal G., op. cit., 1956.

17. Casal J. M., and Casal G., op. cit., p. 42-43, 1956.

18. Wheeler R. E. M., "Brahmagri and Chandravalli 1947: Megalithic and Other Cultures in the Chitaldurg District, Mysore state", Ancient India, vol. 4, p. 199-207, 1948.

19. Deo S. B., "Megalithic problems of the Deccan" South Asian Archaeology, 1981, ed. Allchin B., p. 221-224, 1984.

20. Begley V., Lukacs J., and Kennedy K. A. R., "Excavations of iron age burials at Pomparippu, 1970", Ancient Ceylon, vol. 4, p. 75, 1981.

21. Begley V., "Archaeological sites located at Kottaimedu near Puranasingapalayam and Sorapattu", Pon-Ka-Ma-Ya, 18, Oct. 1993b.

22. Sundara A., "Studies in the Neolithic culture in TamilnaduKerala: an appraisal”, Tamil Civilization, vol 5(2), p. 47, 1987.

23. Wheeler R. E. M, et al., op. cit., p. 104, 1946.

24. Begley V., "Changing Perceptions of Arikamedu”, Begley V., et al., The Ancient Port of Arikamedu: New Excavations and Researches 1989-1992. vol. I, p. 13, 1996. 